\title{
Implementing Time-Driven Activity-Based Costing (TDABC) in out-patient nursing depart- ment: A case from UAE
}

\author{
Nabeel Al Amiri ${ }^{a^{*}}$ and Seham EI Khmidi ${ }^{\mathrm{a}}$
}

a Outpatient Nursing Department, Tawam Hospital, Al Ain, UAE

\begin{tabular}{|c|c|}
\hline CHRON I C L E & A B S T RACT \\
\hline $\begin{array}{l}\text { Article history: } \\
\text { Received: October 7, } 2018 \\
\text { Received in revised format: No- } \\
\text { vember } 29,2018 \\
\text { Accepted: December 16, } 2018 \\
\text { Available online: } \\
\text { December 18, } 2018 \\
\text { Keywords: } \\
\text { Scientific Management } \\
\text { Activity Based Costing (ABC) } \\
\text { Full-Time Equivalent (FTE) } \\
\text { TDABC } \\
\text { Nursing } \\
\text { Healthcare Cost }\end{array}$ & $\begin{array}{l}\text { The UAE diversification strategy of the economy focuses on reducing the dependence of country } \\
\text { GDP on oil. As a result, the healthcare sector has significantly transformed from total dependence } \\
\text { on government health facilities and support to the involvement of the private sector as an essential } \\
\text { partner in covering the health needs of the UAE population. In this emerging competitive market, } \\
\text { the leaders of both public and private healthcare sectors work on several strategies to improve the } \\
\text { effectiveness and the competitiveness of their organizations. Literature shows that nearly } 50 \% \text { of } \\
\text { the hospital's expenses are directed to cover employees' salaries. On the other hands, skilled em- } \\
\text { ployees' salaries are increasing day by day. Thus, we believe that hospitals should deal smartly } \\
\text { with this debate by ensuring using maximum manpower resources. In this study, we present a } \\
\text { nursing project that adopted Fredrick Taylor concepts and used the Time-Driven Activity-Based } \\
\text { Costing (TDABC) methodology to calculate costs and compare its outcome to the currently im- } \\
\text { plemented Full-Time Equivalent (FTE) system in the outpatient unit at Tawam Hospital. The study } \\
\text { findings have confirmed that TDABC can be implemented successfully and make a difference in } \\
\text { human resources management of nurses at the unit level. The authors have recommended rolling } \\
\text { out the study to inpatient nursing units. }\end{array}$ \\
\hline
\end{tabular}

O 2019 by the authors; licensee Growing Science, Canada

\section{Introduction}

The main aim of today's business management is to maximize the organization's profits. This could happen in two ways; first, by reducing the cost of the products or services e.g. to use alternative and cheaper materials, redesign the production/ or service delivery processes, and the use of new machines and technology and second, by increasing sales and revenues e.g. to target new markets (customers) and adopt effective marketing strategies.

Healthcare sector overall the world provides high technical service that is essential to the community's well-being that, in its turn, will have a significant positive impact on the country's economy and Gross Domestic Product (GDP). According to Porter and Lee (2013), all health care systems around the world strain with rising costs of care and uneven quality. Advanced economies like the U.S., Europe, and Japan spend about $12 \%$ of their GDP on health care, e.g., the U.S. is accounting for $\$ 3$ trillion, while the developing countries spend around $6 \%$ of their GDP on health care (Thomas \& Wise, 2015).

* Corresponding author.

E-mail address: alamirinabeel@hotmail.com (N. Al Amiri) 
The large numbers of health workers in the world make up an essential part of the total world labor force. The WHO (2006) report from 64 countries showed that $42.2 \%$ of government health expenditure had been paid to health workers included wages, salaries, and allowances. Around $67 \%$ of those health workers were health service providers. Patrick (2014) found that nearly half (49\%) of the hospital's expenses were directed to cover employee's salaries. While the rest covered, other costs included supply expenses, bad debt expenses, and miscellaneous expenses. More, the study showed that $32 \%$ cover clinical salaries, $30 \%$ cover nurse's salaries, $24 \%$ cover nonclinical employees, and $14 \%$ cover physician's salaries.

On the other hand, Thungjaroenkul et al. (2007) conducted a systematic review between 1990 and 2006. Around 17 studies found that the higher registered nurse (RNs) ratio, e.g., RNs to patients or RNs to other nursing staff is inversely related to costs. According to the International Council of Nurses (ICN) (2015), Nurses, as the single largest profession in the health workforce, are well positioned to drive efficiency and effectiveness improvements while providing quality care and attaining optimal patient and population outcomes. The ICN is committed to improve health systems around the world by developing a proper nursing understanding of healthcare management skills such as strategic planning, financing, budgeting, and resource allocation in order to lead from the front line as the force for change and as cost-effective and care active professionals. In the UAE, the healthcare organizations also struggle to cope with the government strategies of privatization that encouraged private investments in the healthcare sector. Besides, the government health facilities adopted many strategies that improve financial effectiveness. For example, Abu Dhabi Health Services Company [SEHA] (n.d.), the largest UAE healthcare net, has established a strategic priority for itself "to increase financial efficiency by controlling operating expenses and improving Revenue Cycle Management performance". This requires evaluating all resources included in the patient's care, such as personnel, assets, and processes in order to understand its impact on health care service and the entire organization's financial performance. According to the Health Authority of Abu Dhabi [HAAD] (2015) report, around 7,389 nurses (34\% of the total nurses of Abu Dhabi Emirate) are working at SEHA healthcare facilities. Those nurses try to utilize their knowledge and skills to introduce several initiatives to achieve SEHA strategic priority of increasing financial efficiency by controlling operating expenses. Also, they try to be a force for change, care-effectiveness, and cost-effectiveness.

This paper presents a retrospective trial of improving individual and team's productivity of nurses in the outpatient's nursing unit at Tawam Hospital, one of the largest SEHA hospitals, and reallocating nurses accurately to different clinics. To achieve their goal, a group of proactive nurses proposed an idea to monitor nurse's productivity by calculating the time spent on direct patient's care activities instead of the Full Time Equivalent (FTE) monitoring system that use a standard time ratio for each patient's visit e.g. 0.5 hour for every patient regardless the real-time that spent on the care of that patient. The idea of Tawam Hospital outpatient nurses is an implementation of the Time-Driven Activity-Based Costing (TDABC) methodology and a translation of Fredrick Taylor principles of scientific management.

\section{Literature Review}

\subsection{Principles of Scientific Management}

A soon as the first industrial revolution ended in 1830, a second Industrial Revolution, the Technological Revolution, started in 1870 until 1914. According to Mokyr and Strotz (1998), this period was characterized by the invention of new technological systems in energy, materials, chemicals, and medicine and the widespread of innovation in manufacturing and the establishment of a machine tool industry and others had a significant impact on production and increased the effectiveness of research. 
In this period, specifically in 1911, Fredrick Taylor completed most of his famous work on production and management. Taylor (1913, p. 5) said in his book: "The Principles of Scientific Management" that people can see natural resources such as forests, water, soil, coal, and iron are going to waste", but the larger daily wastes of human effort are blundering, ill-directed, or inefficient. To prove his concept for the need for more efficiency, Taylor (1913, P. 5) used President Roosevelt (1858 -1919) statement "The conservation of our national resources is only preliminary to the larger question of national efficiency".

Taylor (1913, pp. 6 -11) tried to show the defect in the past concept of the captains of industry is born, not made. According to him, no great man can with his old system of personnel management compete with some adequately organized ordinary men. In addition, he proposed that the management should secure the maximum prosperity for the employer and employees by developing each employee to a state of maximum efficiency which his natural abilities fit him. The maximum prosperity can be achieved when the work is done with the minimum combined expenditure of human effort, nature's resources, and capital in the shape of machines, buildings, etc. According to Taylor (2013, p. 25), the workmen do their job in many different ways. However, there is always one method which is quicker and better than others that could be developed through a scientific analysis of all available methods with accurate, minute, time and motion study. Scientific management is general principles that gradually substitute the rule of thumb, and it can be applied in different ways. The scientific management as summarized by Taylor (1913, p. 140) are:

- Science, not the rule of thumb

- Harmony, not discord

- Cooperation, not individualism

- Maximum output, in place of restricted output.

- To develop each man to his highest efficiency and prosperity.

Furthermore, science (Taylor, 1913, p. 116) is developed by simple analysis and time study of the movements required by workers to do some small part of their works as follows:

1. Find some specialized and skillful workers from the different establishment or parts of the country for analysis.

2. Study the specific series of elementary operations or motions which is used by each man to do the work.

3. Study with a stopwatch the time required for each of these simple movements.

4. Select the quickest way of doing each element of the work and eliminate all false, slow, and useless movements.

5. Then, collect in one series the quickest.

Later in 1916, Henry Fayol (1949), the father of modern management, divided work activities to technical, commercial, financial, security, accounting, and managerial activities. For every type of activity, special abilities are required that include physical, mental, moral qualities, general education, specialized knowledge, and experience. Also, Fayol (as cited by ÇELİK and Dogan, 2011) tried to increase productivity in large enterprises by implementing Taylor principles such as labor defining, standards and specialization of workers, functions such as organization, planning, controlling and coordination in management. His Management Process Approach, like Scientific Management, takes productivity, economic efficiency, and rationalism as a basis.

\subsection{Traditional Costing vs. Activity-Based Costing}

Calculating the costs of a product or a service requires considering both direct and indirect costs. Direct costs are defined in the Business dictionary as "the expenses that are traced directly to a specific cost 
department, process, or product". Those costs, also called variable costs, including costs for labor, material, or fuel or power which are fixed for every single unit of production but vary as the total output of production increases or decreases. While, indirect costs are defined as the expenses that cannot be assigned to a specific cost department, function, or product. Those costs also called fixed costs or overhead costs, such as costs for maintenance, security, supervision, and rents which are fixed over a period of time, e.g., a month or a year. Traditionally, most of the businesses allocate overhead costs to the products or service on the basis of volume such as the number of units (products), the direct labor costs, the direct labor hours, or the production machine hours (Wilkinson, 2013). The next example shows how to use traditional costing methods as explained by Wilkinson (2013). In addition, we will add three formulas that use direct labor hour as the cost driver to help readers to understand the concept.

1. Estimate indirect (overhead) costs for a period of time, e.g., a month, a quarter, or a year.

2. Use labor hours as the cost-driver.

3. Estimate the amount of the labor hours for the selected period of time

4. Estimate the indirect (overhead) costs for the selected period of time

5. Compute the predetermined overhead rate as follow

$$
\text { Overhead Rate }=\text { Estimated Overhead Costs } \div \text { Total Direct Labor Hours }
$$

6. Apply overhead to products using the predetermined overhead rate.

$$
\text { Overhead Costs }=\text { Direct Labor Hours } x \text { Overhead Rate }
$$

7- Estimate the total traditional cost as follow

$$
\text { Traditional Cost }=\text { Direct Material Costs }+ \text { Direct Labor Costs }+ \text { Overhead Costs }
$$

Although it is easy to use the traditional costing methods, it is still believed that it has several disadvantages; it allocates costs based on a single volume measure such as direct labor hours or machine hours, and it is inaccurate when overhead is high compared to direct costs (Edwards, 2008, p. 4). The activity-based costing ( $\mathrm{ABC}$ ), also known as Operational Activity Based Management, is an alternative to the traditional costing method. According to Kaplan and Burns (1991), ABC has emerged as an extraordinary method that guides managers to improve activities that are related directly to profits and will have the most significant impact on the company's net income. Unlike a traditional costing system, $\mathrm{ABC}$ segregates the indirect expenses and assigns those expenses based on the drivers of the activities to lower costs and improve asset utilization (Kaplan \& Burns, 1991). In contrast to ABC that focus on identifying the cost of activities related to production, the "Activity-Based Management (ABM)" focuses on the analysis of managerial activities that drive organizational processes and goals in order to eliminate non-value-added activities (Gosselin, 2007). Kaplan and Burns (1991) proposed a structured way of connecting the activities and the resources they consume that is called "The ABC Hierarchy". It gives managers an opportunity to distinguish activities at the unit level, e.g., direct labor and material, batch level, e.g., purchase order and inspection, product level, e.g., process engineering and product designing, and facility level, e.g., facility management and building maintenance.

Edwards (2008, pp. 5-6) has listed four steps to implement ABC:

1. Identify all outputs for which that consume resources such as products, services or customers.

2. Identify all activities through in-depth analysis of the operational processes that are required to produce an output.

2. Assign resource costs to activities considering the three categories; Direct, Indirect, and general/administration costs.

4. Assign activity costs to outputs using activity drivers to assign activity costs to outputs based on the consumption or demand for activities. 
An ABC system is flexible; it provides a more accurate method of costing of products and services and highlights costly activities that could be managed differently to reduce costs (Edwards, 2008, p. 7). Furthermore, Chea (2011) in a literature review has concluded that ABC can be used as a useful tool in the service sector to determine accurate costs and help the firm make better decisions. In medical services, Kazemi and Zadeh (2015) found that ABC is a suitable tool to determine the cost price for services. It allows determining the costs of each activity and therapy, or a combination of therapies. Also, it is suggested to use the information on cost price based on $\mathrm{ABC}$ on determining tariffs for medical services. Another study conducted in an Iranian hospital by Javid et al. (2016) found that costs are allocated to cost object based on the patient-days. According to their results, application of the ABC system helps to quantify the actual costs of activities. In addition, they found that human resources were the largest component of total cost of the Iranian hospital and $(29 \%)$ of the total cost was spent on the outpatient departments compared to $48 \%$ of consumed resources were spent on the inpatient departments. Thus, the authors recommended using accurate unit cost calculation and $\mathrm{ABC}$ information of medical service is critical to improve efficiency and transparency in the hospital. Although ABC reported several benefits, it also reported drawbacks, for example, it is time consuming, costly, and it is difficult to assign some overhead costs to products or services (Edwards, 2008, p. 7)

\subsection{Full-time Equivalent (FTE) Methodology}

Full-time equivalent is defined in the business dictionary as the ratio of the total number of paid hours, either part time, full time, or contracted, during a period, e.g., a week, by the number of working hours in that period. An FTE is calculated by dividing the working hours of an employee by the number of working hours that one full-time employee works per a period of time minus annual leaves, sick leaves, and etc. For example, an employee who works 40 hours per week is $1.0 \mathrm{FTE}$ if the full-time employee is 40 hours per week and an employee who works 20 hours per week is 0.5 FTE (Orient Point Consulting LLC, 2016). In this case, the FTE is a number between 0 and 1. In one study of calculation of FTE in fisheries, Salz et al. (2005) defined working time as "the time spent on fishing and related activities on board or shore". Thus, they recommended collecting data regarding the number of hours of actual work on board for each activity per day per man. With respect to health care facilities, the State of West Australia Department of Health (2017) reported that most of the nursing administrations measure nurse staffing as full-time equivalent (FTE) that consider nursing hours per patient day (HPPD) or the ratio of RNs to patients, e.g., $1 \mathrm{RN}$ to every 5 patients. Theoretically, the nurse-to-patient ratio should be calculated by using productive direct patient care nursing hours (Spetz et al., 2008). If each patient day comprises 24 hours, then:

$$
\frac{\text { Nurses }}{\text { Patients }}=\frac{\text { Productive Nursing Hours }}{\text { Patient Days } \times 24},
$$

where:

- Productive hours mean the actual work hours, exclusive of vacation, holidays, sick leave and any other absences.

- Nursing hours per inpatient day means the total number of productive hours worked by nurses with direct patient care responsibilities, divided by the total inpatient days.

- Total patient days are the sum of each daily inpatient census for the time period examined.

The FTE calculation is usually done by comparing nurse staffing levels to international standards. Those benchmarks are obtained by surveying clinical practice of a broad group of units and hospitals. Finding an appropriate benchmark is not always easy. According to Akscin et al. (2007), it can be challenging to find meaningful specialty-specific data to use in the benchmarking process associated with oncology practices. In addition, the State of West Australia Department of Health (2017) encouraged nursing managers to consider some important factors when implementing an FTE methodology in measuring nurse staffing, for example, to consider the indirect hours, the administrative or non- 
nurse functions, the inefficiency of the system and process, and the practice environment which could distract nurses from providing patient care.

\subsection{Time-Driven Activity-Based Costing (TDABC)}

According to Kaplan and Anderson (2003) implementing ABC has its own difficulties that could be due to how people construct their ABC models. These difficulties arise when trying to use $\mathrm{ABC}$ in large organizations on an ongoing basis, which require assigning extra resources to complete this job. More, the cost-driver rates as estimated per the ABC are usually higher than the actual utilization of the capacity. Thereafter, Kaplan and Anderson (2003) proposed a simplified model called time-driven $\mathrm{ABC}$ to help companies estimate the cost of each transaction, product, or customer by using time as a cost driver of activities and the number of times an activity is performed for allocating resources to a different cost center. Cooper (1997) and Cooper and Kaplan (1991) highlighted that the TDABC method considers simple estimation of the time (duration) of each task and multiply it by the number of tasks and then by the hourly cost rather than spending time on surveying employees about how long they spend on different activities. In addition, the TDABC eliminates the complex stage of allocating resource costs to activities before driving them to cost objects, and it can be easily used to measure the amount of time used for most resources such as personnel and equipment (Kaplan \& Anderson, 2007).

TDABC model uses two sets of estimates; it calculates the cost of supplying resource capacity and estimates the demand for resource capacity that each cost object requires. The TDABC model implementation is suggested by Kaplan and Anderson (2007, pp. 43-58) as follows:

- Calculate the cost of all resources such as personnel, occupancy, supervision, equipment, etc., which are supplied to a specific cost center.

- Estimate the practical capacity of resources supplied (it is usually measured by time unit) required for all employees to perform the work.

- Divide the calculated cost of all supplied resources by the practical capacity of resources supplied to obtain the capacity cost rate as per the equation below.

$$
\text { Capacity cost rate }=\frac{\text { Cost of capacity supplied }}{\text { Practical capacity of resources supplied }} .
$$

- Estimate demand for resource capacity that is the time required to perform particular activities.

- Multiply the time required to perform the activity by the amount of the activity and then by the capacity cost rate.

It is important to point out that the practical working capacity is a percentage that lay from 80 to $85 \%$ of theoretical capacity. For example, an employee is working around 20-22 days per month out of 30 days and spends around 384 minutes out of 480 minutes of daily duty time on work activities. While the rest, nearly 70 minutes, is spent on other activities such as meetings, training, and education. Therefore, the monthly practical capacity for each employee is $20-22$ days multiplied by 380 minutes (Kaplan \& Anderson, 2007, pp. 50-51). In one systematic review that included twenty-five articles, Keel et al. (2017) concluded that TDABC is applicable in health care and it could capture the cost of care delivery in a better way in order to create value in health care.

According to Gervais et al. (2010), the concept of TDABC is not adequately explored in academic research. It is only limited to some presentations by the TDABC method designers, few researches and case studies. Furthermore, the absolute advantages of the TDABC are still not confirmed. Although Gervais et al. (2010) argued that using TDABC would not add new value to calculating the cost of capacity and the deviation, they still recommend it as a monitoring method of labor time. 


\section{Purposes of the Study}

In this paper, the authors will present a trial of the outpatient nursing unit at Tawam Hospital that adopted Fredrick Taylor concepts and used the Time-Driven Activity-Based Costing (TDABC) methodology to calculate the outpatient's nurse's costs and compare its outcome to the current implemented FTE system.

\subsection{Primary Goal}

The primary goal of the paper is to investigate the effect of TDABC model for estimating the costs of nursing resources and allocation of these resources to different clinics in comparison with the existing FTE system.

\subsection{Study Objectives}

To achieve their primary goal, a group of proactive outpatient's nurses put a set of objectives as follows:

- Implement the TDABC model in the outpatient nursing unit at Tawam Hospital beside the current existing FTE method.

- Compare the outcome of both methods.

- Discuss the impact of each method on making decisions related to cost management and resource allocation.

- Evaluate the outpatient's nursing leader's experience and feedback with respect to the outcome of the implemented trial.

\subsection{Study Questions}

- Is TDABC an easily implemented and accepted methodology of cost calculation and resource allocation in outpatient's nursing unit?

- Does the outcome of TDABC differ from the outcome of the FTE method?

- Does the TDABC accurately support management decision-making in comparison to FTE method?

- What are the outpatient's nursing manager's experience and feedback in respect to the outcome of the implemented trial?

\section{The Significance of the Study}

Generally speaking, the healthcare sector is struggling to maximize profits by reducing the cost of health care services and increasing the number of patients. Nurses at Tawam Hospital are committed to use and allocate human nursing resources efficiently. The authors expect that the outcome of implementing the TDABC will add value to the strategic planning, budgeting, and allocation of the nurse's resource in the outpatient's unit.

\section{Methodology}

\subsection{Study design}

This study used both quantitative and qualitative methods (Mixed method) to evaluate the outcome of the nurse's trial to improve cost management and human resource allocation in the outpatient unit at Tawam Hospital. The quantitative data were collected from the outpatient's manager's office related to staffing costs and conducted a focused group meeting with 5 nurses who had a supervisory role to get their feedback regarding the outcome of the trial. 


\subsection{Population and Sampling}

The study conducted in the outpatient nursing unit at Tawam Hospital. The outpatient unit has 10 wings with a total of 74 Nurses who provide direct specialized care. To achieve the goal and objectives of the study, the authors analyzed data that in connection with all nurses, called the whole sample, cost at the outpatient nursing unit. Also, they selected a sample of 5 nurses, called purposive sample, who had a supervisory role in the outpatient unit to evaluate the outcome of the trial.

\subsection{Data collection}

A retrospective quantitative data which are related to a nurse's human resource allocation and the calculated productive time was collected from the nursing manager's office of the outpatient's unit in January and February 2018. These data were collected earlier from each clinic and entered into a preprepared excel sheet. For the focused group meeting, a structured interview technique was used to collect the required feedback.

\subsection{Inclusion and Exclusion Criteria}

Data related to the 8-hour nurse's day duty were included in this study. While other data related to evening or weekend's duty were excluded except for the family medicine clinic that did daily evening shift. The main reason for this decision was most of the evening clinics were not constant and vary according to clinical needs. More, the data used were related to the direct nursing care activities and excluded the supervision activities which were not within the scope of this trial.

\subsection{Ethical Consideration}

This study was reviewed and approved by Tawam Hospital's Ethical Committee. The authors have adhered to ethical research standards during the study times.

\section{Implementation}

This project was initiated in response to a debate that took place among nurses at Tawam Hospital Polyclinics. On the one hand, some nurses argued that they overwhelmed with a lot of tasks that exceed their capabilities depending on the high number of patients they see in their clinics on a daily basis. On the other hand, some nurses were unsatisfied as they believe that they see fewer number of patients, but they were with the higher level of complexity and care needs. Furthermore, senior nursing administrative believed that the human resource that allocated to the outpatient nursing department exceeded the actual needs and it could be used more efficiently. Initially, the activity-based concept was suggested as a nurse's productivity measure tool. Later, it was adopted as a methodology that could replace the current FTE methodology that allocates human resource using the 0.5 hours per one patient formula. Therefore, a team of 3 charge nurses was assigned to look how to try the new concept appropriately in the outpatient's nursing unit by considering the minimum disruption of the work environment. The trial was implemented at Tawam hospital outpatient department (polyclinics) that consists of 14 wings with different sub specialties. The trial included 10 wings that report to one nursing manager who was impressed with the concept and agreed to support. Those clinics were pediatric, medicine, surgery, diabetes, orthopedic, ophthalmology, ENT, dermatology, family medicine, and the neuroscience center.

The assigned team conducted the following actions:

a) The concept was introduced to all nurses through unit meetings, presentations, and emails. In those meetings, nurses addressed all their concerns that are related to the implementation procedure of the new model. 
b) A list of all nursing activities was prepared with an average time (called standard time) that's spent by an average skilled nurse to perform an activity. The standard time for each activity was calculated by measuring the time spent on completing one activity by several nurses in different clinics and, then, dividing the sum of time spent on the activity by the frequency of the performing that activity. For example, a group of 10 nurses measured the time, which they consumed to complete nursing assessment specifically $8,10,12,10,9,11,13,9$, and 10 . Thereafter, we calculated the average time (standard time) as follows:

The Average Time (Standard Time) in Minutes $=8+10+12+10+9+11+9+13+9+10 / 10$

$$
=101 \div 10=10.1 \text { minutes for each assessment }
$$

Table 1 presents an example list of the most common nursing activities, which are performed in the outpatient department.

c) A spread excels sheet was created with the required formulas to calculate nurses productive time. The most important two key formulas are

$$
\text { 1) Total Productive Time }=F_{1} S_{1}+F_{2} S_{2}+F_{3} S_{3}+\ldots \ldots \ldots \ldots+F_{n} S_{n}
$$

where: $F_{1}=$ Frequency of activity one per working period, e.g., day, week, or month and so on $\mathrm{S}_{1}=$ Standard time for activity one and so on

2) Percentage of Actual Working Time = Total Productive Time in hours $\div$ Total Duty Time in hours

d) A group of nurses was trained on using the excel sheet and enter data on a daily basis. The time required to enter data for a group of nurses is around 15 minutes. The excel sheet will generate the final scores and reports automatically for each nurse, team, and the whole unit.

e) Nurses are requested to report their activities (self-reporting) on a daily basis to the assigned nurse. The expected percentage of actual working time for each nurse, team, or the whole outpatient's unit is $80 \%$.

f) It is important to mention that the data collected in the first 6 months were not used to judge on nurses productivity or clinic nurses' needs as some nurses did not report their activities as required. Oppositely, it was used to identify barriers to implementation, motivate nurses to participate, and to streamline the process.

\section{Table 1}

Example list of the nursing activities, which are performed in the outpatient's department with the estimated average times

\begin{tabular}{lll}
\hline & Activity & Standard Time in minutes \\
\hline 1. & Adult Patient's Assessment & 10 \\
2. & Pediatric Patient's assessment & 15 \\
3. & Dressing - Minor & 15 \\
\hline 4. & Dressing - Major & 30 \\
5. & Minor surgery & 30 \\
6. & Direct admission to hospital & 45 \\
7. & Applying Cast & 30 \\
8. & Assisting in Laser & 20 \\
9. & Injections, IM, SC & 15 \\
10. & Vaccines & 30 \\
11. & Vision test & 5 \\
\hline
\end{tabular}

\section{Data Analysis}

\subsection{Background Information about Outpatient's Unit Nurses}

Table 2 shows information about the nurses working in the concerned outpatient's unit. A total of 75 nurses was included in this study. 
Table 2

Background information about the outpatient nurses

\begin{tabular}{|c|c|c|c|}
\hline \multicolumn{2}{|l|}{ Category } & Frequency & Percentage \\
\hline \multirow[t]{2}{*}{ Gender } & Female & 63 & 84.00 \\
\hline & Male & 12 & 16.00 \\
\hline \multirow[t]{2}{*}{ Position } & $\mathrm{RN}$ & 47 & 62.67 \\
\hline & AN & 28 & 37.33 \\
\hline \multirow[t]{6}{*}{ Nationality } & Arab Nationality & 20 & 26.67 \\
\hline & GCC & 1 & 1.33 \\
\hline & Philippine & 18 & 24.00 \\
\hline & India & 34 & 45.33 \\
\hline & UAE & 1 & 1.33 \\
\hline & Indonesia & 1 & 1.33 \\
\hline \multirow[t]{10}{*}{ Clinic } & Orthopedic Clinic & 10 & 13.33 \\
\hline & ENT Clinic & 4 & 5.33 \\
\hline & Ophthalmology Clinic & 6 & 8.00 \\
\hline & Dermatology Clinic & 4 & 5.33 \\
\hline & Pediatric Clinic & 9 & 12.00 \\
\hline & Neuroscience Center & 6 & 8.00 \\
\hline & Medicine Clinic & 8 & 10.67 \\
\hline & Family Medicine & 12 & 16.00 \\
\hline & Diabetic Center & 8 & 10.67 \\
\hline & Surgery Clinic & 8 & 10.67 \\
\hline \multicolumn{2}{|c|}{ Total number of nurses } & 75 & 100.00 \\
\hline
\end{tabular}

The statistics obtained from the sample of the included nurses shows that the majority $(84 \%)$ of the outpatient's nurses was females and the rest (16\%) was males. Around two-thirds were registered nurses $(\mathrm{RN})$, and nearly one third was assistant nurses (AN). Also, the data show that around one half (45\%) was Indians, around one quarter was from Philippine, and one quarter was from different Arab countries. Nurse's distribution to the different clinics was as follows: 12 nurses (16\%) to the family medicine clinic; $10(13 \%)$ to orthopedic clinic; $9(12 \%)$ to pediatric clinic; $8(10.7 \%)$ for each of diabetic, surgery, and medicine clinic; $6(8 \%)$ for each of neuroscience center and ophthalmology clinic; and $4(5 \%)$ for each of ENT and dermatology clinics. It is important to mention that no ready data was available on nurse's ages.

\subsection{Analysis of Nurse's Data at Individual Level}

Unfortunately, the only available individual nurses costing data were obtained about the TDABC system. No individual nurses costing data were available on the FTE system. TDABC for every nurse was calculated by dividing the Total Activity's Time by the Total Working time. Table 3 shows the productivity of all nurses and clinics (teams) by percentages. It is evident that the results vary among nurses and clinics (teams).

Table 3

Percentages of nurse's productivity for both months (January and February 2018)

\begin{tabular}{lccccccccccccc}
\hline Clinics & 1 & 2 & 3 & 4 & 5 & 6 & 7 & 8 & 9 & 10 & 11 & 12 & Total \\
\hline Orthopedic Clinic & 63 & 58 & 65 & 84 & 82 & 60 & 80 & 73 & 63 & 77 & & 71 \\
ENT Clinic & 78 & 83 & 81 & 82 & & & & & & & & 71 \\
Ophthalmology Clinic & 79 & 74 & 81 & 70 & 86 & 72 & & & & & 77 \\
Dermatology Clinic & 55 & 79 & 84 & 80 & & & & & & & & \\
Pediatric Clinic & 70 & 71 & 70 & 42 & 65 & 83 & 74 & 81 & 74 & $51 *$ & $85^{*}$ & \\
Neuroscience Center & 75 & 109 & 94 & 88 & 83 & 85 & & & & & & 72 \\
Medicine Clinic & 82 & 81 & 80 & 73 & 83 & 76 & 64 & 79 & & & 59 & 79 \\
Family Medicine Clinic & 32 & 73 & 58 & 13 & 69 & 70 & 58 & 64 & 58 & 53 & 56 & 61 & 59 \\
Diabetic Center & 69 & 56 & 61 & 61 & 81 & 67 & 68 & 30 & & & & & 63 \\
Surgery Clinic & 81 & 82 & 66 & 74 & 64 & 65 & 67 & 65 & & & & 70 \\
\hline
\end{tabular}

*Two nurses moved to pediatric from meuroscience center.

Table 4 presents the descriptive analysis of the nurse's outcomes. The mean is 0.71 , which is less than the target (0.8); the standard error is 0.017 (close to zero and less than the SD), which means the test reliability is high (close to 1 ) at a $95 \%$ confidence interval; standard deviation is 0.144 (close to zero), 
N. Al Amiri and S. El Khmidi / Management Science Letters 9 (2019)

and also it means that the spread of data tends to be close to the mean; Kurtosis is 3.85 (above 3), which reflects a stronger peak compared with normal distribution; and Skewness is -1.23 , which reflects a long tail of the left side of the distribution than the tail on the right side (see Fig. 1 for the histogram).

\section{Table 4}

Descriptive analysis of available data related to TDABC

\begin{tabular}{llll}
\hline Mean & 0.71 & Skewness & -1.229 \\
Standard Error & 0.017 & Range & 0.9598 \\
Median & 0.726 & Minimum & $0.126(\%)$ \\
Standard Deviation & 0.144 & Maximum & $1.086(\%)$ \\
Sample Variance & 0.021 & Sum & 52.86674801 \\
Kurtosis & 3.845 & Count & 75 \\
\hline
\end{tabular}

Fig. 1 illustrates the distribution of the actual work outcome (illustrated in black) of the 75 nurses in comparison to the target outcome (illustrated in grey). It shows that the majority of nurses did not reach the target that is $80 \%$. Table 5 shows our classification of nurses outcome; it shows that the majority $(69 \%)$ of the outpatient nurses used working time inefficiently, around $4 \%$ of the nurses reached their work target, and around one quarter $(27 \%)$ of the nurses exceeded the target. More, Table 5 shows a negative balance of a total 1,475 hours, which were not used efficiently for direct patient care. Those remaining hours were calculated by subtracting the target working hours from the actual outcome hours for every nurse, and then the balances of all nurses were summed up.

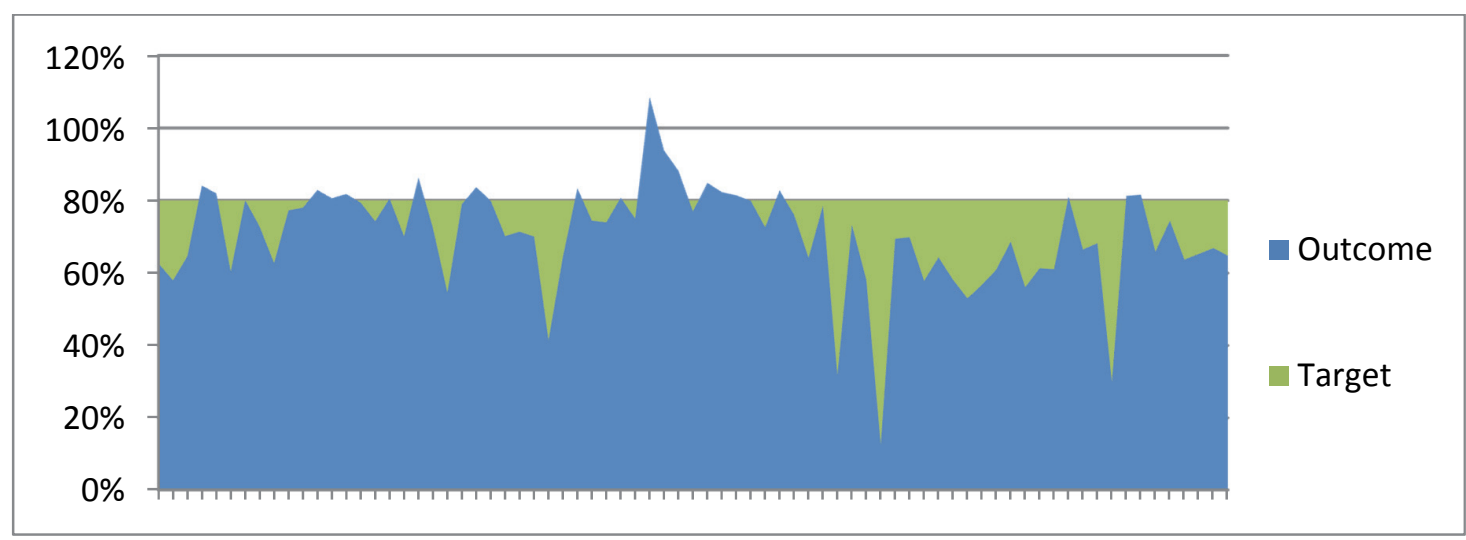

Fig. 1. Actual nurse's outcome in comparison to the target outcome as calculated by TDABC system

Table 5

Analysis of individual nurses outcome as calculated by TDABC system

\begin{tabular}{lllll}
\hline Category & Description & No. of Nurses & Percentage & Balance in hours \\
\hline Less than $60 \%$ & Very Low & 12 & 16.00 & -653.8 (Less than the target) \\
$60-79 \%$ & Low & 40 & 53.33 & $-1,010.1$ (Less than the target) \\
$80 \%$ & Average [Target] & 3 & 4.00 & 0.3 (Zero) \\
$81-100 \%$ & High & 19 & 25.33 & 150.4 (More than the target) \\
Above $100 \%$ & Very High & 1 & 1.33 & 38.7 (More than the target) \\
Total & & 75 & 100.0 & $-1,474.5$ hours (Loss) \\
\hline
\end{tabular}

To determine the cost of the 1,475 hours in AED (The United Arab Emirates Dirham), a predetermined cost rate of nurse's time was estimated as follow:

The predetermined cost rate $=$ Total nurse's cost in AED $\div$ Total nurse's hours (in a period of time).

In our case:

The predetermined cost rate per hour (as estimated for one month) $=1,487,900$ AED $\div 21008$ hour $=$ 71 AED per hour

Then, the 1,475 hours was multiplied by the predetermined cost rate as follows.

Loss $=1,475 \times 71=104,725$ AED (in January and February 2018) 


\subsection{Comparison between the Outcome of TDABC and FTE Methods}

Table 6 presents a comparison between the TDABC and FTE calculations. The TDABC calculations show that orthopedic, pediatric, family medicine, diabetic center, and surgery clinics did not use the assigned working time productively, while medicine, ophthalmology, and dermatology clinics were very close to the target. Also, it shows that the ENT clinic and neuroscience center exceeded the target. In reference to FTE calculations, i.e., time in hour/No. of patients seen, the table shows that ENT, dermatology, neuroscience, medicine, and diabetic clinics were in shortage, while the pediatric clinic was very close to the target. Also, it shows that orthopedic, surgery, and ophthalmology clinics had more nurses than the expected target. It is evident that the two calculation systems gave different outcomes, which can lead to different management decisions regarding assigning staff to different clinics.

\section{Table 6}

Comparison between the Outcome of TDABC and FTE Methods for January and February 2018

\begin{tabular}{lcccccccc}
\hline & \multicolumn{3}{c}{ FTE } & \multicolumn{4}{c}{ TDABC } \\
\cline { 2 - 9 } Clinic & Time In & No. of & Outcome & Target & Time In & Time Out & Outcome (\%) & Target (\%) \\
\hline Orthopedic Clinic & 2806 & 3309 & 0.85 & 0.5 & 2,885 & 2049 & 71.02 & 80.00 \\
ENT Clinic & 1109 & 2740 & 0.40 & 0.5 & 1,199 & 969 & 80.81 & 80.00 \\
Ophthalmology Clinic & 1714 & 2890 & 0.59 & 0.5 & 1,625 & 1,256 & 77.32 & 80.00 \\
Dermatology Clinic & 924 & 3859 & 0.24 & 0.5 & 1,010 & 802 & 79.41 & 80.00 \\
Pediatric Clinic & 2052 & 3921 & 0.52 & 0.5 & 1,928 & 1,402 & 72.71 & 80.00 \\
Neuroscience Center & $909^{*}$ & $2420^{*}$ & 0.38 & 0.5 & $854^{*}$ & $761^{*}$ & 89.11 & 80.00 \\
Medicine Clinic & 1674 & 5066 & 0.33 & 0.5 & 1,861 & 1,464 & 78.67 & 80.00 \\
Family Medicine & 3021 & 6963 & 0.43 & 0.5 & 2,949 & 1,737 & 58.90 & 80.00 \\
Diabetic Center & 1951 & 5288 & 0.37 & 0.5 & 1,626 & 1,023 & 62.92 & 80.00 \\
Surgery Clinic & 1797 & 3007 & 0.60 & 0.5 & 1,962 & 1,380 & 70.34 & 80.00 \\
Total & 17957 & 39463 & 0.46 & 0.5 & 17,899 & 12,843 & 71.75 & 80.00 \\
\hline
\end{tabular}

*Data was available for one month only that is January 2018

Furthermore, the comparison between the two calculation systems as presented in Fig. 2 and 3 shows that the FTE system indicates adding more nurses, while the TDABC system indicates decreasing nurses (or increasing activities) at the outpatient's unit level.

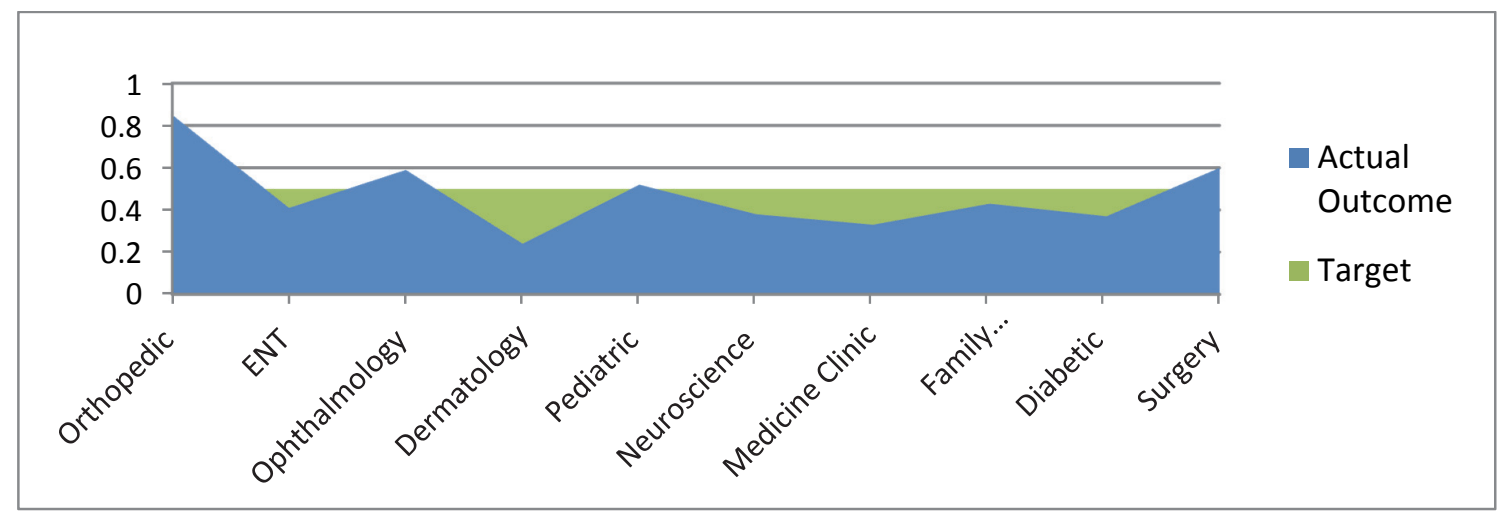

Fig. 2. All clinics' outcomes as calculated by the FTE system

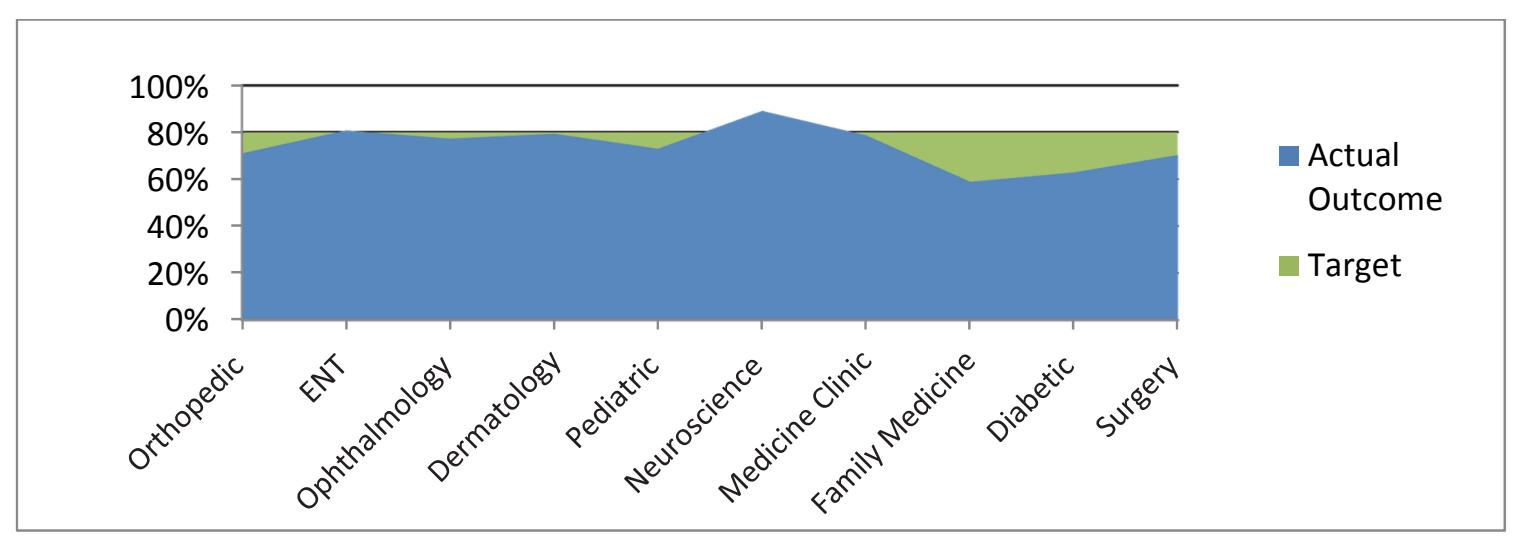

Fig. 3. All clinics' outcomes as calculated by the TDABC system 


\subsection{Analysis of Senior Nurses Feedback}

To evaluate the outpatient nurse's feedback, the authors conducted a focused group discussion with 5 nurses who had a supervisory role in the outpatient nursing unit to evaluate their experience and get their feedback. The discussion focused on evaluating the benefits and difficulties of implementing TDABC and the extension of usage data for quality improvement projects.

According to participant observation, nurses became more focused on taking a more proactive part in providing direct patient care than before. They said nurses became faster and more efficient in using work time. Furthermore, the TDABC calculations gave them accurate data to use for staff annual appraisal discussion, improve those who were low, and recognize those who were highly productive.

In the opinion of participants, implementation of TDABC was associated with some difficulties. Participants specified that some direct care staff were assigned to do extra administrative tasks in addition to their direct patient care activities and spent time on non-nursing functions such as solving problems related to appointment booking and registration errors, etc. Also, they spoke about a gap in communication between project leaders and front line staff through team leaders and representatives, which influenced the front line staff understanding of the TDABC concept negatively. Another critical issue was mentioned by participants was the negative attitude of some front line staff when they received comments regarding their productivity. Finally, the authors found that the vast amount of TDABC data were poorly used to initiate quality projects to improve the work environment, processes, and redesigning the workflow.

\section{Discussion}

The summary of the findings of the literature review has provided us with the available knowledge as found in academic books and journals on different costing calculating systems. TDABC, as proposed by Kaplan and Anderson (2003), is found as one of the exciting costing systems that has many advantages, and appropriate to be used in the healthcare sectors as most of the expenses are assigned an employee's salary (Patrick, 2014) including nurses who form the largest proportion of all healthcare employees.

Depending on our analysis of the data that we have obtained from the outpatient nursing unit manager, it is found that the TDABC system gave more detailed information about what nurses are doing on a daily basis. This information includes types of activities; the time consumed for each activity; and nurses who do the work. Also, it identifies the activities that consume time unnecessarily, nurses who need development, and the skills that are required to raise work efficiency. Another significant advantage of the detailed unit level data is guiding nurses to conduct many quality improvement projects to modify work processes, redesign workspaces, and redistribute nurses to different work locations. In comparison to the easy implemented and nationally benchmarked FTE methodology that is currently used in the outpatient nursing unit, the TDABC system gives more detailed data than the FTE calculation system.

One important result that needs to be explained is the variation between the time inputs in the calculation of both FTE and TDABC as presented in Table 6. Theoretically, the input should be equal in both calculations. But in actual fact, staffs float to help in other clinics for short periods of time and some human errors in calculating and entering data are the main reasons that stand behind this variation at the clinic's level. However, comparing the total time inputs at the outpatient's unit level reveals the variation is not significant.

Table 7 explains how the managerial decision varies according to the costing system used to calculate human resources expenses at different clinic's level and the whole outpatient nursing unit level. For 
orthopedic, neuroscience, and surgery clinics, the decisions are similar per the two systems. For the rest of the clinics, i.e., ENT, ophthalmology, dermatology, pediatrics, medicine, family medicine, and diabetic clinics, the decision is significantly changed. Also, it is evident that the decisions changed at the whole outpatient nursing unit level.

Table 7

Comparison of the managerial decisions according to the costing calculation system

\begin{tabular}{lcccccc}
\hline & \multicolumn{3}{c}{ FTE } & & \multicolumn{2}{c}{ TDABC } \\
\cline { 2 - 7 } Clinic & $\begin{array}{c}\text { Outcome } \\
(\%)\end{array}$ & $\begin{array}{c}\text { Target } \\
(\%)\end{array}$ & $\begin{array}{c}\text { Staffing Deci- } \\
\text { sion }\end{array}$ & Outcome (\%) & Target (\%) & Staffing Decision \\
\hline Orthopedic Clinic & 0.85 & 0.5 & Decrease & 71.02 & 80.00 & Decrease \\
ENT Clinic & 0.40 & 0.5 & Increase & 80.81 & 80.00 & Keep \\
Ophthalmology Clinic & 0.59 & 0.5 & Decrease & 77.32 & 80.00 & Keep \\
Dermatology Clinic & 0.24 & 0.5 & Increase & 79.41 & 80.00 & Keep \\
Pediatric Clinic & 0.52 & 0.5 & Keep & 72.71 & 80.00 & Decrease \\
Neuroscience Center & 0.38 & 0.5 & Increase & 89.11 & 80.00 & Increase \\
Medicine Clinic & 0.33 & 0.5 & Increase & 78.67 & 80.00 & Keep \\
Family Medicine & 0.43 & 0.5 & Increase & 58.90 & 80.00 & Decrease \\
Diabetic Center & 0.37 & 0.5 & Increase & 62.92 & 80.00 & Decrease \\
Surgery Clinic & 0.60 & 0.5 & Decrease & 70.34 & 80.00 & Decrease \\
Total & 0.46 & 0.5 & Increase & 71.75 & 80.00 & Decrease \\
\hline
\end{tabular}

The authors believe the managerial decisions that made depending on data generated by the TDABC system are more appropriate for cost management in the outpatient nursing unit than the data calculated by the FTE system. This is justified merely by the fact that TDABC calculation depended on the actual specific unit care activities rather than international benchmarks.

About the outpatient's unit nurses feedback as evaluated by the focused group discussion, we agree that some difficulties are associated with implementing the TDABC system. Most of these difficulties are related to nurses resistant to change, poor understanding of the concept, and leadership gaps. Despite these difficulties and barriers were at the minimum, we found no serious actions were taken to use the TDABC system data in quality improvement of the work process, workflow, or staff development that could be related to lack of leadership skills such and the desire to spend more time on improving. Finally, the TDABC calculation consumes more time than the FTE system. This challenge should not fall nurses back. They should always consider the advantages of detailed data that they could get from implementing the TDABC.

\section{Conclusion}

Our literature review highlighted many benefits of the TDABC system over the other costing systems. The outcome of this study at Tawam Hospital outpatient nursing unit has supported the previous conclusions regarding the efficiency of the TDABC system. We have found that it gives more detailed information that could benefit nurses to improve their work environment and use their time efficiently. Furthermore, it could guide managers to make more accurate decision regarding human resources cost management. Although the TDABC system has some difficulties, we have found that it was implemented successfully in the outpatient's nursing units and made a difference in human resources cost management.

\section{Recommendation}

The study findings support implementing TDABC system as a solution for accurate calculation of nurse's cost and allocation of human resource correctly to different cost locations (clinics). Therefore, nursing managers should be wise enough to manage difficulties rather than frustration and giving up. They should assess the work environment and adopt a flexible implementation strategy that aims to 
persuade nurses using the information to cooperate and consider it as an opportunity for personal and unit improvement. Along with that, managers should consider incremental or adjustment strategy of staffing, depending on the new data rather than taking major swift actions. Since the TDABC calculation system consumes more time than the FTE system, the authors suggest using the available health information system to generate the required reports that relate to different nurse's activities. Finally, the authors recommend implementing TDABC for calculating the indirect supervision cost of the outpatient nursing unit of Tawam Hospital as well as trialing it in inpatient's units.

\section{Acknowledgment}

The authors thank Prof. Manuel Fernandez from Skyline University College for sharing his expertise with us and suggesting useful comments on a preliminary version of the manuscript. This work is also well supported by Tawam Hospital nursing administration, nursing research office, and all nurses of the outpatients' unit.

\section{References}

Abu Dhabi Health Services Company [SEHA] (n.d.). Our strategic priorities, retrieved June 16, 2018 from https://www.seha.ae/English/aboutus/Pages/strategies-and-objectives.aspx

Akscin, J., Barr, T. R., \& Towle, E. L. (2007). Benchmarking practice operations: Results from a survey of office-based oncology practices. Journal of Oncology Practice, 3(1), 9-12.

Celik, M., \& Dogan, E. (2011). A theoretical approach to the science of management. International Journal of Humanities and Social Science, 1(3), 66-69.

Chea, A. (2011). Activity-based costing system in the service sector: A strategic approach for enhancing managerial decision making and competitiveness. International Journal of Business and Management, 6(11), 3 .

Cooper, R. (1987). The two-stage procedure in cost accounting-part one. Journal of Cost Management, 1(2), 43-51.

Cooper, R., \& Kaplan, R. S. (1991). Profit priorities from activity-based costing. Harvard business review, 69(3), 130-135.

Direct costs, Business dictionary, retrieved June 26 ${ }^{\text {th }}, 2018$ from http://www.businessdictionary.com/definition/direct-cost.html

Edwards, S. (2008). Activity Based Costing, CIMA, retrieved June 27 $7^{\text {th }}, 2018$ from http://www.cimaglobal.com/Documents/ImportedDocuments/cid_tg_activity_based_costing_nov08.pdf.pdf

Fayol (1949). General And Industrial Management, Sir Isaac Pitman \&Sons Ltd, London, pp. 3-7, (Original work published 1916), retrieved July $2^{\text {nd }}$, from https://archive.org/details/in.ernet.dli.2015.13518

Full-time equivalent (FTE), Business Dictionary, retrieved June 25 $5^{\text {th }}, 2018$ from http://www.businessdictionary.com/definition/full-time-equivalent-FTE.html

Gervais, M., Levant, Y., \& Ducrocq, C. (2010). Time-Driven Activity-Based Costing (TDABC): An Initial Appraisal through a Longitudinal Case Study. Journal of Applied Management Accounting Research, 8(2), 1-20

Gosselin, M. (2006). A review of activity-based costing: technique, implementation, and consequences. Handbooks of management accounting research, 2, 641-671.

Health Authority Abu Dhabi (2016), Health Statistics 2015, p. 28, retrieved on June 17, 2018 from https://www.haad.ae/HAAD/LinkClick.aspx?fileticket=gzx_WUkD27Y\%3d\&tabid=1516

Indirect costs. Business dictionary, retrieved June $28^{\text {th }}, 2 \overline{0} 18$ from http://www.businessdictionary.com/definition/indirect-cost.html

International Council of Nurses (2015). Nurses: A Force for Change Care Effective, Cost Effective, $p$. 1, retrieved June 17, 2018 from https://www.mzcr.cz/Soubor.ashx?souborID=23018.../pdf...pdf

Javid, M., Hadian, M., Ghaderi, H., Ghaffari, S., \& Salehi, M. (2016). Application of the activity-based costing method for unit-cost calculation in a hospital. Global Journal of Health Science, 8(1), 165. 
Kaplan, R. S., \& Anderson, S. A. (2003). Time-driven activity-based costing. http://dx.doi.org/10.2139/ssrn.485443

Kaplan, R. S., \& Anderson, S. R. (2007). Time-driven activity-based costing: a simpler and more powerful path to higher profits. Harvard business press.

Kazemi, Z., \& Zadeh, H. A. (2015). Activity based Costing: A Practical Model for Cost Price Calculation in Hospitals. Indian Journal of Science and Technology, 8(27), 1-6.

Keel, G., Savage, C., Rafiq, M., \& Mazzocato, P. (2017). Time-driven activity-based costing in health care: A systematic review of the literature. Health Policy, 121(7), 755-763.

Mokyr, J. (1998). The second industrial revolution, 1870-1914. Storia dell'economia Mondiale, 21945.

Orient Point Consulting LLC (2016). FTE Definition, calculation, and analysis, retrieved June $25^{\text {th }}$, 2018 from http://www.orientpoint.com/FTE.htm

Patrick, M. (2014). Analyzing hospital expenses: Breaking down the important costs, retrieved June $23^{\text {rd }}, 2018$ from http://marketrealist.com/2014/11/analyzing-hospital-expenses/

Porter, M., \& Lee, T. H. (2013). The strategy that will fix health care, Harvard business review, retrieved from https://hbr.org/2013/10/the-strategy-that-will-fix-health-care

Salz, P., Buisman, E., Malvarosa, L., Daures, F., Andersen, J. L., Andersen, K. N., ... \& Curtis, H. (2005). Calculation of labour including FTE (full-time equivalent) in fisheries. FISH/2005/14.

Spetz, J., Donaldson, N., Aydin, C., \& Brown, D. S. (2008). How many nurses per patient? Measurements of nurse staffing in health services research. Health Services Research, 43(5p1), 1674-1692.

State of West Australia Department of Health (2017). Nursing Hours per Patient Day: an overview, retrieved June 20 $0^{\text {th }}, 2018$ from https://ww2.health.wa.gov.au/Articles/N_R/Nursing-hours-per-patient-day

Taylor, F. W. (1913). The principles of scientific management, Harper \& Brothers publishers, New York \& London, retrieved from https://ia800502.us.archive.org/13/items/principlesofscie1911tayl/principlesofscie1911tayl.pdf

Thomas, J. M. \& Wise, S. H. (2015). 2016 Global Healthcare Outlook, the Carlyle Group, p. 1, retrieved June 17, 2018 from https://www.carlyle.com/sites/default/files/market-commentary/october_2015 - global_health_care_investment_outlook.pdf

Thungjaroenkul, P., Cummings, G. G., \& Embleton, A. (2007). The impact of nurse staffing on hospital costs and patient length of stay: a systematic review. Nursing Economics, 25(5), 255.

WHO (2006). Health workers: a global profile, p. 7, retrieved July 20 $0^{\text {th }}$, 2018 from http://www.who.int/whr/2006/06_chap1_en.pdf

Wilkinson, J. (2013). Activity-based Costing (ABC) vs. Traditional Costing, retrieved June $26^{\text {th }}, 2018$ from https://strategiccfo.com/activity-based-costing-abc-vs-traditional-costing/

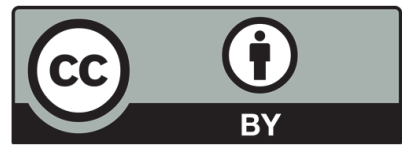

(C) 2019 by the authors; licensee Growing Science, Canada. This is an open access article distributed under the terms and conditions of the Creative Commons Attribution (CC-BY) license (http://creativecommons.org/licenses/by/4.0/). 